\title{
Atypical skin graft-vs.-host disease following bone marrow transplantation in an infant
}

\author{
Kuskonmaz B, Güçer S, Boztepe G, Cetin M, Uckan D. Atypical skin \\ graft-vs.-host disease following bone marrow transplantation in an \\ infant. \\ Pediatr Transplantation 2007: 11:214-216. @ 2007 Blackwell Munksgaard \\ Abstract: Herein, we describe an unusual presentation of acute graft \\ versus host disease (GVHD) mimicking contact dermatitis in an infant \\ who underwent 5/6 HLA-matched bone marrow transplantation \\ (BMT) from his mother for malignant infantile osteopetrosis. The initial \\ rash on day +32 simulated diaper rash, which progressed to a belt- \\ shaped rash and then developed hyperkeratotic nodules on the hands. \\ The acute GVHD was atypical and the course was progressive and fatal, \\ with liver and gut involvement. This presentation of atypical initial skin \\ involvement of acute GVHD may be useful for practicing clinicians in \\ the BMT field who need to be aware of the early unusual signs of acute \\ GVHD so that they can initiate prompt treatment.
}

\author{
B. Kuskonmaz ${ }^{1}$, S. Güçer ${ }^{2}$, \\ G. Boztepe ${ }^{3}, M$. Cetin ${ }^{1}$ and D. Uckan ${ }^{4}$ \\ Departments of ${ }^{1}$ Pediatric Hematology, ${ }^{2}$ Pediatric \\ Pathology and ${ }^{3}$ Dermatology, and ${ }^{4}$ Pediatric Bone \\ Marrow Transplantation Unit, Hacettepe University, \\ Ankara, Turkey \\ Key words: bone marrow transplantation - \\ dermatitis - graft-vs.-host disease - skin GVHD \\ Duygu Uckan, HaceHepe University Children's \\ Hospital, Hematology/Bone Marrow Transplantation \\ Unit, Yenisehir, Ankara 06100, Turkey \\ Accepted for publication 16 October 2006
}

\section{Introduction}

GVHD is one of the most important complications of allogenic HSCT, and despite tremendous efforts in prevention and treatment, it is still associated with significant morbidity and mortality. The skin, gastrointestinal tract, and liver are the organs primarily affected (1). The skin is typically the first site of involvement (2). Clinically, acute cutaneous GVHD is characterized by a maculopapular rash, reticulate rash, bullous lesions, and erythroderma that involves the palms and soles, and as the disease progresses, the upper trunk, neck, cheeks, and ears become involved (3-5). Early recognition of GVHD is of critical importance for undertaking necessary measures to prevent progression to a life-threatening condition. Herein, we present a fivemonth-old infant with osteopetrosis who developed localized skin acute GVHD, which initially mimicked contact dermatitis, and progressed to grade IV disease (involving skin, the gastrointestinal system, and liver) following bone marrow transplantation (BMT) from his 5/6 HLA-

\footnotetext{
Abbreviations: GVHD, graft-vs.-host disease; HSCT, hematopoietic stem cell transplantation; i.v., intravenous; GCSF, granulocyte-colony stimulating factor; BMT, bone marrow transplantation; VOD, veno-occlusive disease; CyA, cyclosporin A; HLA-DR, human leukocyte antigen DR.
}

matched mother. To the best of our knowledge, there have been no previous reports of localized, belt-shaped acute GVHD.

\section{Case report}

A five-month-old male infant with malignant infantile osteopetrosis underwent allogenic BMT from his HLA-5/6 (DRB1 mismatch) identical mother in January 2005. Molecular methods have been used for HLA typing of class I and class II. The patient had initially presented with hepatosplenomegaly, anemia, thrombocytopenia, leukocytosis, blindness, optic nerve involvement, and mild hydrocephalus. The diagnosis was based on X-ray findings consistent with diffuse osteosclerosis. The parents were first-degree relatives. The conditioning regimen consisted of i.v. busulfex $(3.2 \mathrm{mg} / \mathrm{kg} \times 4 \mathrm{~d})$ and cyclophosphamide $(50 \mathrm{mg} / \mathrm{kg} \times 4 \mathrm{~d})$. GVHD prophylaxis included CyA and methotrexate. CyA was initiated at a dose of $3 \mathrm{mg} / \mathrm{kg} / \mathrm{d}$ (i.v.) on day -2 and was adjusted according to blood level. Methotrexate was given at a dose of $15 \mathrm{mg} / \mathrm{m}^{2}$ on day +1 , $10 \mathrm{mg} / \mathrm{m}^{2}$ on day +3 , and day +6 . Infection prophylaxis consisted of weekly i.v. immunoglobulin at a dose of $400 \mathrm{mg} / \mathrm{kg}$, antifungal (fluconazole), antiviral (acyclovir) prophylaxis, gut sterilization, and metronidazole. Cotrimoxazole treatment began after engraftment. Ursodeoxycholic acid and low-molecular-weight heparin 
were both used for veno-occlusive disease (VOD) prophylaxis. Unmanipulated bone marrow cells, including $4.5 \times 10^{8}$ nucleated cells $/ \mathrm{kg}$ and $2 \times 10^{6}$ CD34 cells $/ \mathrm{kg}$, were given. G-CSF was started at a dose of $5 \mu \mathrm{g} / \mathrm{kg}$ on day +8 . Neutrophil and platelet engraftment $>20 \times 10^{9} / \mathrm{L}$ occurred on days +17 and +35 , respectively. He received antibacterial treatment for neutropenic fever, including cefepime, amikasin, and imipenem. A rise in blood calcium levels during the periengraftment period suggested improving osteoclast function. On day 32, he developed a hyperemic erythematous skin rash over the diaper region that resembled diaper rash, and topical steroids and antifungal treatment were given. Soon after, a localized, belt-shaped hyperemic skin rash on his mid-lower abdominal region was observed, which was also confined to the diaper area (Fig. 1). Three days after the skin rash, hyperemic keratotic lesions developed on the patient's fingers and dorsum of the hands. Systemic methylprednisolone at the standard dose was initiated for possible acute GVHD, which was later confirmed by histopathological examination of skin biopsies obtained from the upper abdominal region and the keratotic lesions on the hand (Fig. 2). The pathological findings showed verrucous hyperplasia and prominent granular layer of the epidermis. There were also focal vacuolization of basal cell layer, spongiosis, scattered dyskeratotic keratinocytes and a few lymphocytes around dermal capillaries. No evident koilocytes or other signs of wart infection was found. The eccrine glands and vessels were normal. A histopathological diagnosis of acral keratotic acute GVHD was made. Although skin lesions regressed, jaundice and elevated liver enzymes were detected on day +37 and diarrhea developed the next day. Acute GVHD rapidly progressed to grade IV disease and the patient died of intractable acidosis despite aggressive treatment consisting of high-dose methylprednisolone, dose-adjusted CyA, anti-IL-2 receptor antibody, and daclizumab.

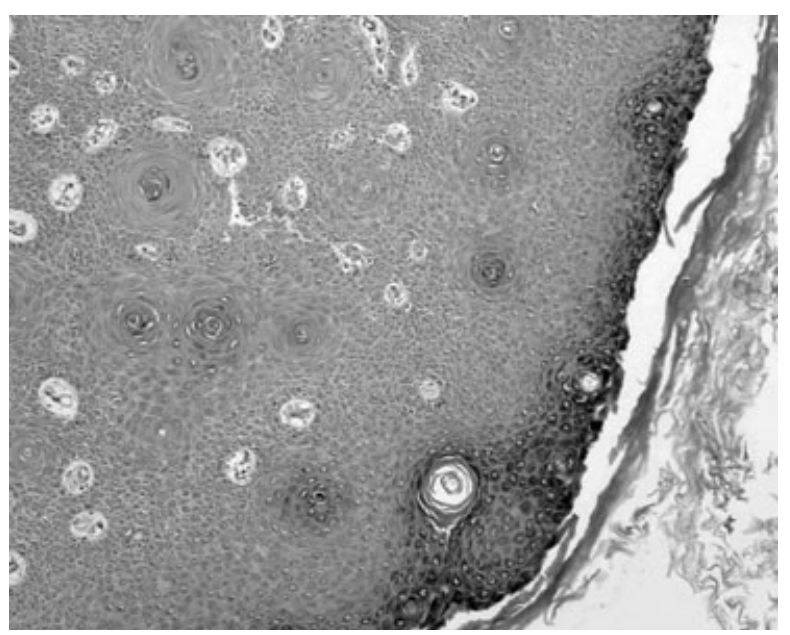

Fig. 2. Vacuolization of basal layer, spongiosis and dyskeratotic keratinocytes in epidermis of tangential section of skin biopsy.

\section{Discussion}

Acute GVHD is the primary or associated cause of death in up to $45 \%$ of BMT patients (6). Acute cutaneous GVHD reaction has been shown to develop in $50-80 \%$ of allogenic BMTs. GVHD following allogenic BMT is an immunological process in which activated donor lymphocytes mount an attack on recipient tissues (4). In acute GVHD, skin manifestations are usually the first and most frequent findings (7). Arslan et al. reported a $96.5 \%$ rate of skin involvement in acute GVHD (8). In acute GVHD, the most frequent skin manifestation is erythematous eruption with pruritus, and/or a burning sensation involving the palms, soles, earlobes, neck, and upper back. Early lesions are characterized by folliculocentric erythematous pale maculae and papules, and may involve broad areas. In severe acute GVHD, exfoliative dermatitis or toxic epidermal necrolysis-like lesions may also develop $(9,10)$. Unusual dermatological findings such as lichenoid papules, generalized erythema multiforme-like eruption, pustular acral erythema have rarely been reported in acute GVHD
Fig. 1. Belt-shaped hyperemic skin rash and hyperemic keratotic lesions on the fingers and dorsum of the hands.
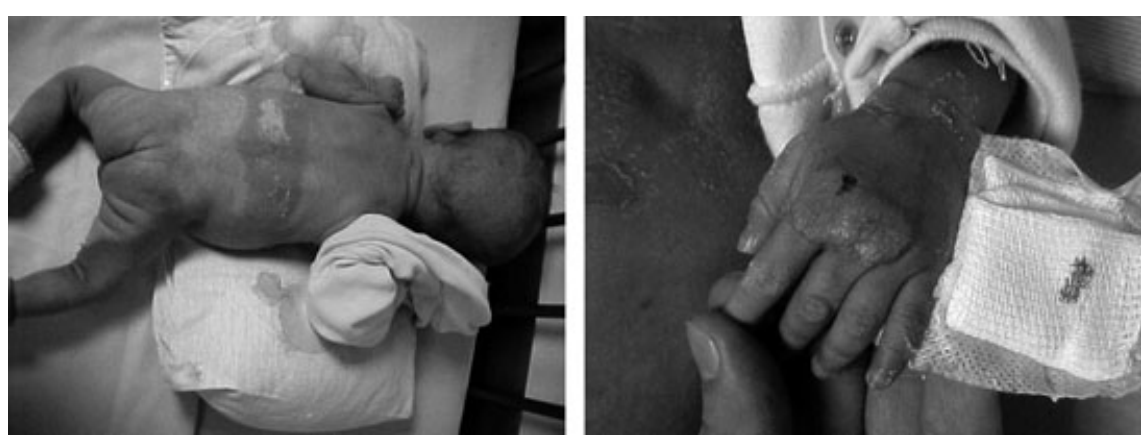
Kuskonmaz et al.

(7, 11). Multiple keratotic lesions resembling warts on the fingers, palms, and soles, resembling our patient's symptoms, have been described in a case in which skin manifestations were observed as a part of chronic GVHD (12). However, the diagnosis in the present case was acute, not chronic GVHD. The initial skin involvement consisting of hyperemic belt-shaped skin lesions on the mid-abdomen resembled diaper rash/ contact dermatitis. Although systemic steroids at a standard dose were given three days after the initial rash and intensive immunosuppressive treatment was administered, progression to a fatal course could not be prevented. The stormy course of acute GVHD in the present case was attributed to HLA-DRB1 allele mismatch with his mother. The presentation of this unusual and fatal case of GVHD with atypical initial skin involvement may be useful for practicing clinicians in the BMT field who need to be aware of the early unusual signs of acute GVHD so that they can initiate prompt treatment.

\section{References}

1. Bolanos-Meade $\mathbf{J}$. Update on the management of acute graftversus-host disease. Curr Opin Oncol 2006: 18: 120-125.

2. Vargas-Diez E, Fernandez-Herrera J, Marin A, Camara R, GARCIA-Diez A. Analysis of risk factors for acute cutaneous graft-versus-host disease after allogeneic stem cell transplantation. Br J Dermatol 2003: 148: 1129-1134.

3. Chaudhuri SP, Smoller BR. Acute cutaneous graft versus host disease: A clinicopathologic and immunophenotypic study. Int J Dermatol 1992: 31: 270-272.

4. Deeg HJ, Storb R. Graft-versus-host disease: Pathophysiological and clinical aspects. Annu Rev Med 1984: 35: 11-24

5. Saurat JH. Cutaneous manifestations of graft-versus-host disease. Int J Dermatol 1981: 20: 249-256.

6. Storb R, Prentice RL, Buckner CD, et al. Graft-versus-host disease and survival in patients with aplastic anemia treated by marrow grafts from HLA-identical siblings. Beneficial effect of a protective environment. N Engl J Med 1983: 308: 302-327.

7. Sanli H, EкMekci P, Arat M, Gurman G. Clinical manifestations of cutaneous graft-versus-host disease after allogeneic haematopoietic cell transplantation: Long-term follow-up results in a single Turkish centre. Acta Derm Venereol 2004: 84: 296-301.

8. Arslan O, Ustun C, Arat M et al. Allogeneic peripheral blood stem cell transplantation in acute non-lymphoblastic leukemia. Hematol Oncol 1998: 16: 155-162.

9. JoHNSON ML, FARMER ER. Graft-versus-host reactions in dermatology. J Am Acad Dermatol 1998: 38: 369-392

10. Aractingi S, Chosidow O. Cutaneous graft-versus-host disease. Arch Dermatol 1998: 134: 602-612.

11. Ruiz-Genao DP, Gf-Villalta MJ, Penas PF, Fraga J, Garcia-Diez A, Fernandez-Herrera J. Pustular acral erythema in a patient with acute graft-versus-host disease. J Eur Acad Dermatol Venereol 2003: 17: 550-553.

12. Kossard S, MA DD. Acral keratotic graft versus host disease simulating warts. Australas J Dermatol 1999: 40: 161-163. 